\title{
Hyaluronic Acid-zinc Protoporphyrin IX Conjugates for Photodynamic Antitumor Therapy
}

Eguchi K, Nakamura H*, Zhou JR, Jun F, Yokomizo K and Haratake M

Faculty of Pharmaceutical Sciences, Sojo University, 4-22-1 Ikeda Nishi-ku Kumamoto, 860-0082 Kumamoto, Japan

\begin{abstract}
Zinc (II) protoporphyrin IX (ZnPP) strongly inhibits antioxidative enzyme heme oxygenase-1 (HO-1), and ZnPP generates reactive oxygen species (ROS) upon light irradiation. ZnPP can induce lethal oxidative stress in the tumor, when $\mathrm{ZnPP}$ is selectively delivered to the tumor followed by light irradiation. In this study, ZnPP was conjugated to hyaluronic acid (HA-ZnPP) for improving its solubility in aqueous media and tumor selective delivery of ZnPP by the enhanced permeability and retention (EPR) effect. Though photosensitizing activity of the HA-ZnPP was quenched in phosphate buffered saline, it was partially recovered by addition of lecithin. Similar to other polymer-conjugated ZnPP, cellular uptake of the HA-ZnPP was lower than that of the free ZnPP in HeLa cells. In tumor-bearing mice, plasma halflife of HA-ZnPP became longer than that of free ZnPP, and thus selective accumulation of the HA-ZnPP in the tumor by the EPR effect was observed. Combination of the HA-ZnPP and light irradiation potentially suppressed the tumor growth, approximately $60 \%$ tumor volume reduction was observed without apparent adverse effects at day 31 after the drug treatment. These data demonstrate that HA is a preferable carrier for ZnPP, and the HA-conjugated ZnPP is a promising antitumor agent for photodynamic therapy.
\end{abstract}

Keywords: EPR; Hyaluronic acid; Photodynamic therapy; Zinc protoporphyrin; Nanomedicine

\section{Introduction}

Iron metalloporphyrins (heme) are of the highest biological importance, since this family of molecules represents the active site of hemeproteins present throughout living systems, such as hemoglobin and myoglobin. Zinc (II) protoporphyrin IX ( $\mathrm{ZnPP}$ ) is one of the metalloporphyrin derivatives. In ZnPP, zinc (II) atom is inserted into its tetrapyrole ring instead of iron (II) in heme. This conversion of metal in PP has great impact on its physicochemical and biological function of PP such as photosensitizing activity and heme oxygenase inhibition $[1,2]$. ZnPP also has unique properties in terms of antitumor activity.

Under physiological conditions, heme is degraded by heme oxygenase 1 (HO-1), and then ferrous ion, carbon monoxide and biliverdin are produced. Bilirubin, which is produced from biliverdin by biliverdin reductase, shows antioxidative effect, and carbon monoxide shows antiapoptotic effect. Therefore, $\mathrm{HO}-1$ acts as an antioxidative and cytoprotective enzyme in living cells [3-6]. In contrast, ZnPP can inhibit the catalytic action of HO-1, resulting in induction of oxidative stress [7]. Especially, cancer cells are dependent on its antioxidative function of highly expressed $\mathrm{HO}-1$, therefore, cancer cells are more sensitive to ZnPP than normal cells [8].

Reactive oxygen species (ROS) cause cytotoxic damage to various kinds of cells. ROS generating enzymes and compounds have been applied for an effective antitumor therapy $[9,10]$. Photodynamic therapy also utilizes ROS that is generated from photosensitizer, e.g. Photofrin and Laserphyrin upon light irradiation, for solid tumor treatment. Though various porphyrin derivatives are utilized for photodynamic therapy in research, the singlet oxygen $\left({ }^{1} \mathrm{O}_{2}\right)$ quantum yield of $\mathrm{ZnPP}(0.91)$ is higher than other porphyrin derivatives and commercially available photosensitizers, i.e. protoporphyrin IX $(0.56)$, chlorin e6 (0.64) and pheophorbide a (0.69) photofrin (0.89) [11].

$\mathrm{ZnPP}$ possesses preferable properties as an antitumor agent, however, it's extremely poor water solubility and undesirable pharmacokinetics has disturbed its clinical application. To overcome such drawbacks, we have reported water-soluble $\mathrm{ZnPP}$ derivatives using synthetic biocompatible polymers such as poly (styrene-co-maleic acid) (PSMA), poly(ethylene glycol) (PEG) and poly(N-(2-hydroxypropyl) methacrylamide) (PHPMA) [7,12,13]. These polymer conjugates of ZnPP derivatives were water-soluble, and were accumulated in the tumor tissue by EPR effect followed by tumor regression with or without light irradiation. However, cellular uptake and cytotoxicity of the PEG and PHPMA conjugates of ZnPP was lower than those of free ZnPP. In this study, we newly synthesized hyaluronic acid (HA) conjugates of $\mathrm{ZnPP}$ (HA-ZnPP) having both improved tumor accumulation and cellular uptake property, and examined its physicochemical property, cellular uptake, body distribution, and antitumor efficacy using a mouse tumor model.

\section{Materials and Methods}

\section{Materials}

Five-week old male ddY mice were purchased from Kyudo Co., Ltd (Saga, Japan). Protoporphyrin IX and hemin were obtained from SigmaAldrich (St. Louis, MO). Tetrahydrofuran (THF), trimethylamine (TMA), ethylchloroformate (ECF), ethylendiamine (EDA), chloroform, dimethilsulfoxide (DMSO), 4-(4,6-Dimethoxy-1,3,5triazin-2-yl)-4- methyl-morpholinium chloride hydrate (DMTMM), zinc acetate, D-MEM (low glucose), penicillin-streptomycin-glutamine $(\times 100), 0.25 \%$ trypsin-EDTA and lecithin from egg yolk were obtained from Wako Pure Chemical (Osaka, Japan). 2,2,6,6-Tetramethyl-4piperidone (TEMPD) was purchased from Tokyo Chemical Industry (Tokyo, Japan). Hyaluronic acid (HA) was purchased from MRC

*Corresponding author: Hideaki Nakamura, Faculty of Pharmaceutical Sciences, Sojo University, 4-22-1 Ikeda Nishi-ku Kumamoto, 860-0082 Kumamoto, Japan, Tel: +81963264197; E-mail: nhideaki@ph.sojo-u.ac.jp

Received: April 20, 2017; Accepted: April 25, 2017; Published: April 28, 2017

Citation: Eguchi K, Nakamura H, Zhou JR, Jun F, Yokomizo K, et al. (2017) Hyaluronic Acid-zinc Protoporphyrin IX Conjugates for Photodynamic Antitumor Therapy. J Nanomed Nanotechnol 8: 440. doi: 10.4172/2157-7439.1000440

Copyright: ( 2017 Eguchi K, et al. This is an open-access article distributed under the terms of the Creative Commons Attribution License, which permits unrestricted use, distribution, and reproduction in any medium, provided the original author and source are credited. 
Citation: Eguchi K, Nakamura H, Zhou JR, Jun F, Yokomizo K, et al. (2017) Hyaluronic Acid-zinc Protoporphyrin IX Conjugates for Photodynamic Antitumor Therapy. J Nanomed Nanotechnol 8: 440. doi: 10.4172/2157-7439.1000440

Page 2 of 6

Polysaccharide Corp., Ltd (mean Mw $3 \times 10^{3}$ ), Wako Pure Chemical (Hyaluronic Acid Sodium Salt from Rooster Comb, mean Mw $1 \times 10^{6}$ ). A NANOpure Diamond (Thermo Fisher Scientific, Kanagawa, Japan) was utilized to generate water $(18.2 \mathrm{M} \Omega \cdot \mathrm{cm})$, which is used throughout this study. All other chemicals were of commercial reagent or special grades and used as received.

\section{Synthesis of ZnPPED (bis (ethylenediamino) zinc protoporphyrin)}

ZnPPED was synthesized as described previously with slight modification [7]. Briefly, $100 \mathrm{mg}$ of $\mathrm{ZnPP}$ was dissolved in $20 \mathrm{~mL}$ of THF. A mixture of TMA $(0.25 \mathrm{~mL})$ and ECF $(0.34 \mathrm{~mL})$ was dropwisely added to the ZnPP solution followed by stirring for $30 \mathrm{~min}$ on ice. THF, TMA and unreacted ECF were removed by evaporation at $60^{\circ} \mathrm{C}$ under reduced pressure. Activated $\mathrm{ZnPP}$ dissolved in THF was dropwisely added into $0.25 \mathrm{~mL}$ of EDA with vigorous stirring, and the mixture was allowed to react for $30 \mathrm{~min}$ at ambient temperature. Then, THF in the reaction mixture was evaporated, and ZnPPED precipitated was washed with ice water. ZnPPED was further purified by alumina column chromatography using EDA-containing chloroform as an eluent.

\section{Conjugation of $\mathrm{HA}$ and $\mathrm{ZnPP}$}

ZnPPED (8 mg) and HA (100 mg) were dissolved in $12 \mathrm{~mL}$ of DMSO, and $180 \mathrm{mg}$ of DMTMM dissolved in DMSO was dropwisely added with stirring at ambient temperature. Four hours later, the reaction mixture was poured into 10 -fold volume of ethanol to separate HA-ZnPP from the reaction mixture. Precipitated HA-ZnPP was purified by re-dissolving in DMSO and subsequent precipitation in ethanol thrice. HA-ZnPP was further washed twice with ethyl alcohol, and was dried in vacuo.

\section{High performance size exclusion chromatography of HA-} ZnPP

The obtained HA-ZnPP was dissolved in DMF for the following chromatographic analysis. Chromatographic conditions were as follows: detection (415 nm), JASCO UV-2075; pump, PV-2080; column, an Asahipak GF-310 HQ (i.d. $7.5 \times 300 \mathrm{~mm}$ ); mobile phase, DMF; flow rate, $0.5 \mathrm{~mL} / \mathrm{min}$. When ZnPPED was analyzed in the synthesis of ZnPPED from ZnPP, ZnPPED was eluted with a mixture of $30 \%$ DMSO and $70 \%$ methanol containing $10 \mathrm{ppm}$ trifluoroacetic acid at $0.8 \mathrm{~mL} / \mathrm{min}$.

\section{Dynamic light scattering measurement}

HA-ZnPP was dissolved in phosphate-buffered saline, and the sample solution $(0.5 \mathrm{mg} / \mathrm{mL})$ was passed through a $0.45-\mu \mathrm{m}$ pore size cellulose acetate membrane syringe filter (ADVANTEC). The hydrodynamic particle diameter was measured by light scattering using an ELS-Z2 (Otsuka Photal Electronics Co. Ltd., Osaka, Japan).

\section{Electron spin resonance (ESR) spectroscopy}

ESR spectra were measured by using an ESR spectrometer at ambient temperature (JES FA-100; JEOL, Tokyo). Sample solutions containing $0.1-100 \mu \mathrm{g} / \mathrm{ml} \mathrm{HA-ZnPP}$ or free $\mathrm{ZnPP}$ and $20 \mathrm{mM}$ 4-oxoTEMP with or without light irradiation were evaluated. Sample solutions in a flat quartz cell (Labotec, Tokyo) were irradiated (50 mW/ $\mathrm{cm}^{2}$ ) by using xenon light at 400-700 nm (MAX-303; Asahi Spectra, Tokyo) for indicated time period. The ESR spectrometer was usually set at a microwave power of $1.0 \mathrm{~mW}$, amplitude of $100 \mathrm{kHz}$ and field modulation width of $0.1 \mathrm{mT}$.

\section{Cellular uptake of HA-ZnPP}

HeLa cells seeded on a 6 well plate at $2 \times 10^{5}$ cells per well were treated with the HA-ZnPP or ZnPP at a concentration of $10 \mu \mathrm{g} \mathrm{ZnPP}$ equivalent $/ \mathrm{mL}$ for indicated time period. Cells were washed thrice with phosphate buffered saline, and then intracellular drug was extracted by adding $1 \mathrm{~mL}$ of $1 \%$ sodium dodecyl sulfate (SDS) followed by sonication at $60 \mathrm{~W}$ for $20 \mathrm{sec}$. Half milliliter of cell extract was added into $1.5 \mathrm{~mL}$ of DMSO, and the amount of HA-ZnPP or ZnPP was determined by fluorescence spectrophotometer (Ex $420 \mathrm{~nm}, \operatorname{Em} 500-700 \mathrm{~nm}$ ). The amounts of $\mathrm{HA}-\mathrm{ZnPP}$ and $\mathrm{ZnPP}$ were calculated from standard curves of HA-ZnPP and ZnPP, respectively. Protein quantification was carried out using a BCA protein assay kit in accordance with the manufactures instruction. Bovine serum albumin was used for the preparation of protein calibration curve.

\section{Animal handling}

The care and maintenances of mice were carried out according to the institutional guidelines of the Institutional Animal Care and Committee of Sojo University.

\section{Body distribution of HA-ZnPP}

S-180 mouse sarcoma cells $\left(1 \times 10^{6}\right.$ cells $)$ were implanted in the subcutaneous tissue of dorsal skin of 5-week old male ddY mice. When tumor diameter became 5-8 mm, HA-ZnPP or ZnPP was administered by tail vein injection at $15 \mathrm{mg} / \mathrm{kg}$. At $24 \mathrm{~h}$ and $48 \mathrm{~h}$ after drug treatment, mice were sacrificed, and each organ was dissected after perfusion of the vascular void with saline. DMSO $(900 \mu \mathrm{L})$ was added to $100 \mathrm{mg}$ of tissues, and they were homogenized to extract HA-ZnPP or ZnPP. Homogenates were centrifuged at 15,000 rpm for $15 \mathrm{~min}$, and $200 \mu \mathrm{L}$ of supernatant was added to the $2 \mathrm{~mL}$ of $50 \%$ THF in deionized water, and the concentration of $\mathrm{HA}-\mathrm{ZnPP}$ and $\mathrm{ZnPP}$ was fluorometrically determined (Ex: 420 nm, Em: 500-700 nm)

\section{Antitumor activity of HA-ZnPP in mice}

HA-ZnPP or ZnPP was administered to S-180 tumor-bearing mice at a tumor diameter above $5 \mathrm{~mm}$ at $15 \mathrm{mg} \mathrm{ZnPP}$-equivalent $/ \mathrm{kg}$ of via tail vein at an indicated time. At $24 \mathrm{~h}$ after drug administration, tumor-bearing mice in some groups were irradiated with a xenon lamp MX-303 (Asahi Spectra) at $400-700 \mathrm{~nm}\left(20 \mathrm{~mW} / \mathrm{cm}^{2}\right)$ for $5 \mathrm{~min}$. The tumor volumes in $\mathrm{mm}^{3}$ and body weight of mice were measured at appropriate time intervals. Tumor volume was calculated as $\left(\mathrm{W}^{2} \times\right.$ $\mathrm{L}) / 2$, after measuring the length (L) and width (W) of the tumor on the dorsal skin.

\section{Statistical analysis}

Data were presented as mean $\pm \mathrm{SD}$. To determine the significance of obtained result, two-tailed unpaired Student's $t$-test was applied. Results were considered statistically significant when $P$ was less than 0.05 .

\section{Results and Discussion}

\section{Synthesis of HA-ZnPP}

According to the procedure described previously, $\mathrm{ZnPP}$ was derivatized through its carboxyl groups to ZnPPED, [7]. ZnPP was conjugated with HA by dehydration condensation between amino groups of ZnPPED and carboxyl group of HA (Scheme 1). After the reaction, HA-ZnPP was precipitated in ethanol to separate the unreacted ZnPPED and other reactants from the reaction mixture. Purity of HA-ZnPP was checked by high performance size exclusion 

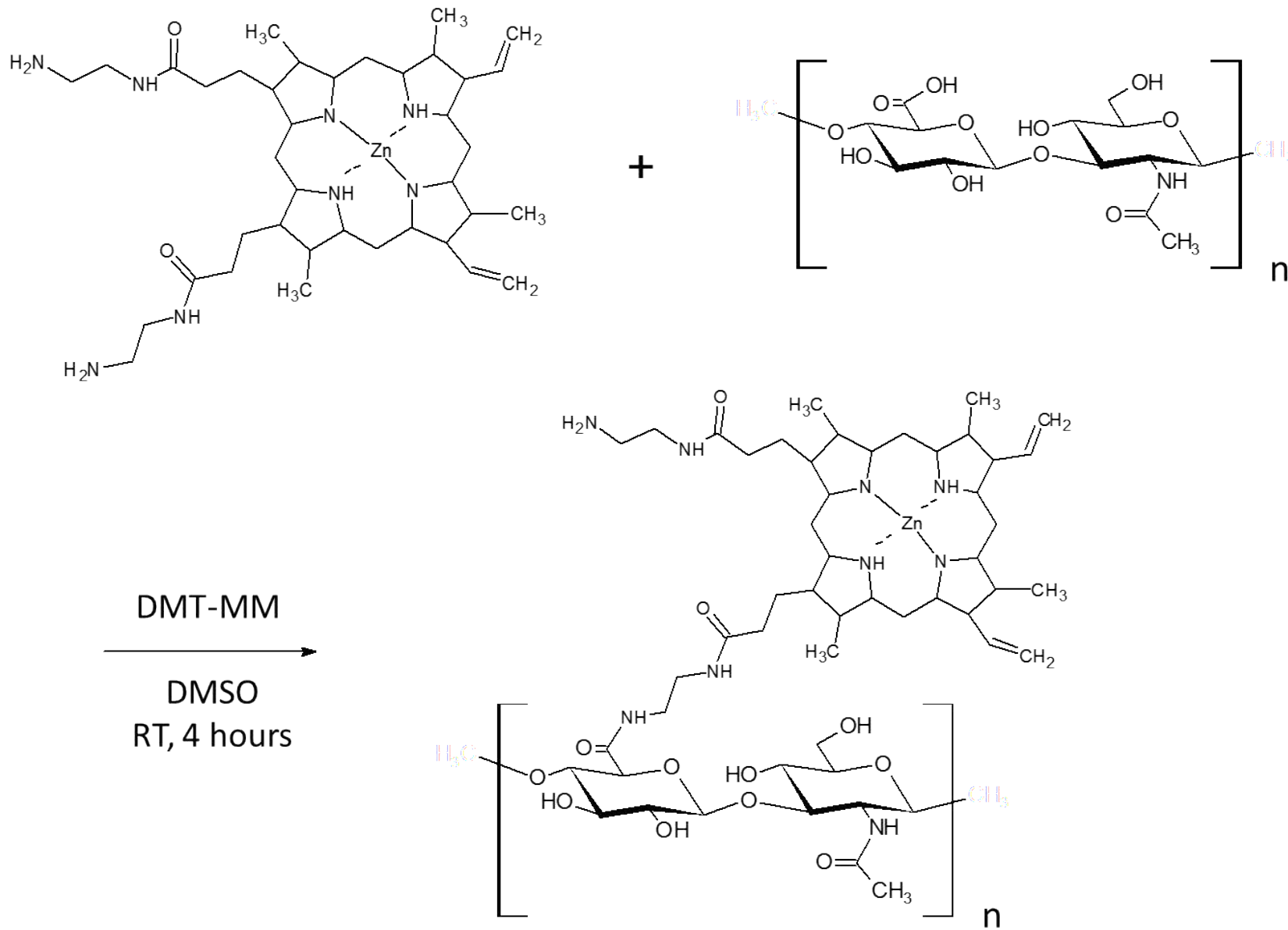

Scheme 1: Conjugation of HA and ZnPP by dehydration condensation.

chromatography. Unreacted residual ZnPPED was not totally detected in the purified HA-ZnPP used for the following experiments. Conjugation of $\mathrm{ZnPP}$ to high molecular weight $\mathrm{HA}\left(\right.$ mean $\mathrm{Mw} 1 \times 10^{6}$ ) resulted in gel formation during the reaction. Instead, when used HA with mean Mw of $3 \times 10^{3}$, no such gel formation was observed. $\mathrm{ZnPPED}$ has two chemically equivalent primary amino groups in its molecular structure. Both amino groups could be possibly reacted intra- and/or inter-molecularly with the carboxyl groups of the HA molecules. When the rate of the free amino groups in the HA-ZnPP from $\mathrm{Mw} 3 \times 10^{3} \mathrm{HA}$ was estimated by TNBS, nearly half of its primary amino groups were remained in the free form. Therefore, the crosslinked species were not thought to be a major portion of the HA-ZnPP. The HA-ZnPP had a solubility of above $10.0 \mathrm{mg} / \mathrm{mL}$ in phosphate-buffered saline (PBS). The conjugation to $\mathrm{HA}$ with mean $\mathrm{Mw} 3 \times 10^{3}$ successfully rendered $\mathrm{ZnPP}$ soluble in aqueous media ( $\mathrm{ZnPP}$ solubility is approximately $0.3 \mathrm{mg} / \mathrm{mL}$ even in a 1:2 mixture of DMSO and PBS). ZnPP loading amount and mean hydrodynamic particle diameters of the HA-ZnPP used for the following experiments were $10.0 \mathrm{wt} \%$ and $156.0 \pm 5.1 \mathrm{~nm}$, respectively.

\section{Photo-physicochemical property of HA-ZnPP}

Visible absorption spectra of HA-ZnPP in various solutions were shown in Figure 1. In aqueous solution such as PBS, HA-ZnPP can forms self-aggregates, and thus the absorption spectra of HA-ZnPP shifted to lower wavelength compared to that in organic solvents such as DMSO and DMF where ZnPP moiety exists in molecularlydispersed state (Figure 1).

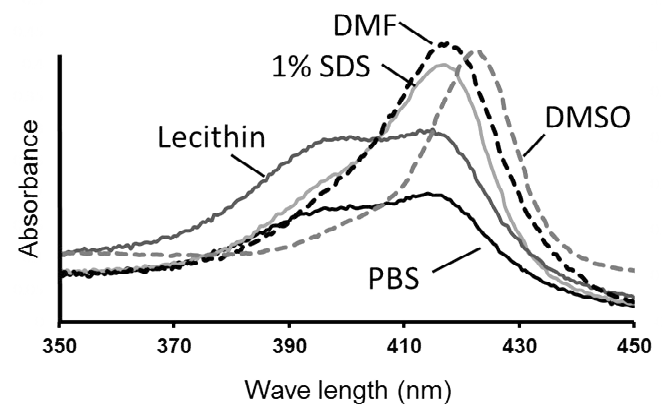

Figure 1: Visible absorption spectra of HA-ZnPP in various solutions

\section{Singlet oxygen generation upon light irradiation}

Various porphyrin derivatives generate the reactive oxygen species, e.g. singlet oxygen $\left({ }^{1} \mathrm{O}_{2}\right)$ upon light irradiation [14]. ZnPP was also reported to show high singlet oxygen quantum yield [11]. Here, we determined the singlet oxygen from the HA-ZnPP using X-band electron spin resonance (ESR) with TEMPD as singlet oxygen trapping agent. HA-ZnPP generate ${ }^{1} \mathrm{O}_{2}$ in organic solvent efficiently, but not in the aqueous solution (Figure $2 \mathrm{~A}$ and 2D). Though, HA-ZnPP also showed least generation of ${ }^{1} \mathrm{O}_{2}$ in aqueous solution, it was partially recovered in the presence of detergent such as lecithin and SDS (Figure $2 \mathrm{~A}-2 \mathrm{C})$. These data indicate that $\mathrm{HA}-\mathrm{ZnPP}$ is photo-physicochemically 
(A) PBS

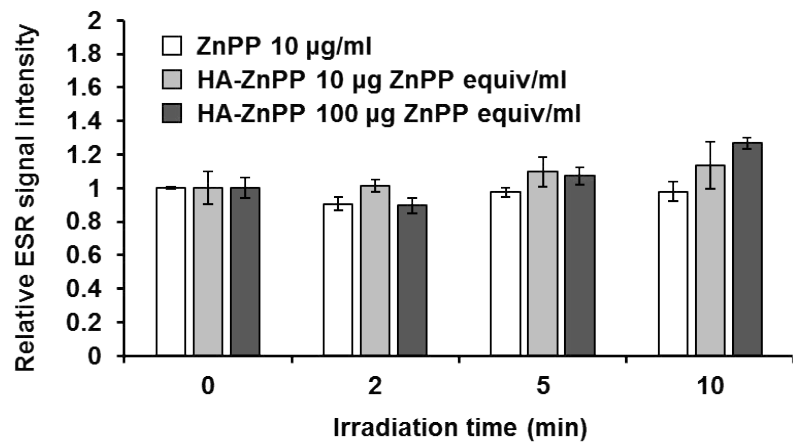

(C) SDS

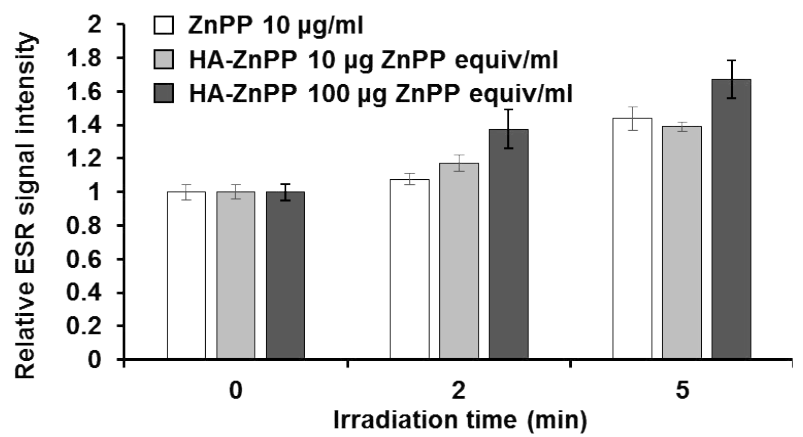

(B) Lecithin

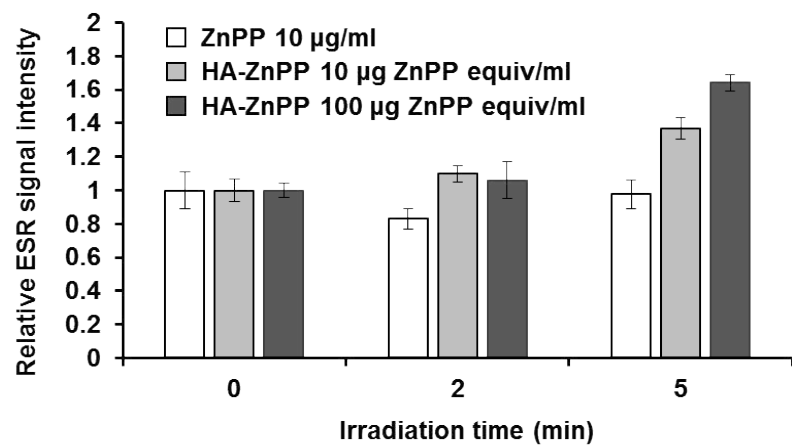

(D) DMF

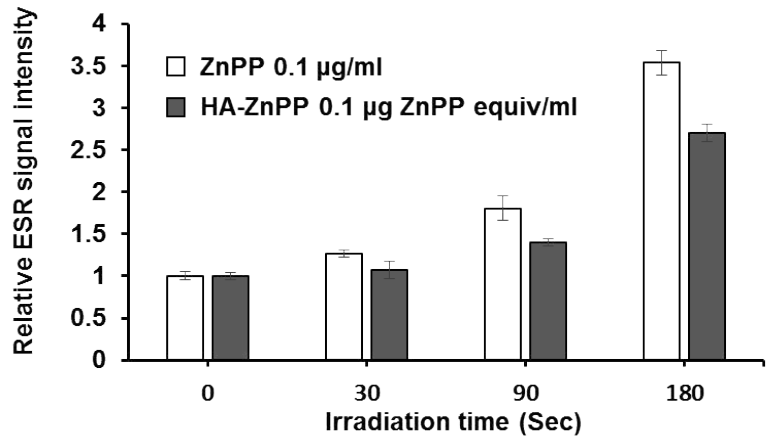

Figure 2: ${ }^{1} \mathrm{O}_{2}$ generation from HA-ZnPP upon light irradiation. ${ }^{1} \mathrm{O}_{2}$ generation from HA-ZnPP and ZnPP dissolved in (A) PBS and PBS containing (B) $0.1 \%$ lecithin, (C) $1 \%$ SDS or (D) DMF. HA-ZnPP or ZnPP solutions were irradiated with a xenon lamp at $400-700 \mathrm{~nm}\left(50 \mathrm{~mW} / \mathrm{cm}^{2}\right)$ for indicated time period. ${ }^{1} \mathrm{O}_{2}$ generated in the solutions was captured by 4-oxo-TEMP, and the resulting 4-oxo-TEMPO was detected by ESR. Data were expressed as relative value to the no light-irradiation control. Data were presented as mean $\pm S D(n=3)$.

inactive in an aqueous solution (no ${ }^{1} \mathrm{O}_{2}$ generation), and would become active when it is internalized into the cells, where HA-ZnPP contact with membrane component, lecithin etc.

\section{Cellular uptake of HA-ZnPP into HeLa cells}

Cellular uptake of drugs is often attenuated by conjugation of biocompatible polymer $[14,15]$. We also reported that the cellular uptake of ZnPP decreased by conjugation to PEG and PHPMA $[13,16]$. Under physiological conditions, high molecular weight HA $\left(\approx 1 \times 10^{6}\right)$ is cleaved with hyaluronidase 2 into its fragments $\left(\approx 1 \times 10^{4}\right)$, and HA fragments produced are internalized by receptor-mediated endocytosis (CD44, RHAMM, LYVE-1 and HARE), and/or non-receptor mediated endocytosis (macro-pinocytosis) [17]. Similar to the conjugation with PEG and PHPMA, the cellular uptake rate of HA-ZnPP was lower than that of free $\mathrm{ZnPP}$ in HeLa cells (Figure 3). To obtain information on the internalization manner of HA-ZnPP into HeLa cells, we examined the cellular uptake of HA-ZnPP in the presence of ZnPP-free HA (same as the starting material used for the conjugation with $\mathrm{ZnPP}, \mathrm{Mw}$ $\left.3 \times 10^{3}\right)$. The cellular uptake rate of HA-ZnPP was supposed to decrease due to the competitive inhibition for the HA receptor. The addition of the ZnPP-free HA actually resulted in a decrease in the cellular uptake rate of HA-ZnPP into HeLa cells, suggesting that the cellular uptake process of HA-ZnPP into HeLa cells involves the HA receptormediated endocytosis. Consequently, HA conjugation could possibly promote the contact of HA-ZnPP to the cell membrane through the HA receptor-mediated endocytosis.

\section{Body distribution of HA-ZnPP in tumor-bearing mice}

Body distribution of intravenously-administered HA-ZnPP was

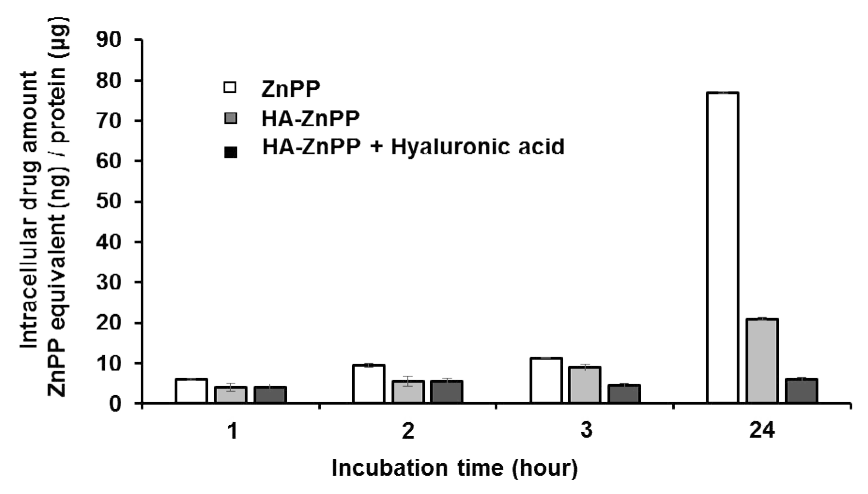

Figure 3: Cellular uptake of HA-ZnPP. HeLa cells seeded on $1.88 \mathrm{~cm}^{2}$ dishes were treated with $\mathrm{ZnPP}$ or HA-ZnPP in the absence or presence of $\mathrm{HA}$ for indicated time period. Intracellular drug amount was determined by fluorescence spectrometry and normalized by the cellular protein amount. Data were presented as mean $\pm S D(n=6)$.

examined in S-180 tumor bearing mice. At $24 \mathrm{~h}$ after the intravenous administration of free $\mathrm{ZnPP}, \mathrm{ZnPP}$ was accumulated in the spleen and much less in the tumor tissue, and mostly eliminated from the blood circulation (Figure 4). Such poor pharmacokinetics of free ZnPP was also confirmed in our previous studies $[7,13]$. Tumor tissue possesses the leaky vasculature and lack the functional lymph vessel, therefore long-circulating biocompatible polymer gradually accumulate in the tumor by enhanced permeability and retention (EPR) effect [18]. The hydrodynamic size of HA-ZnPP was large enough to evade the renal exclusion, and thus HA-ZnPP retained in the blood circulation much 
(A)

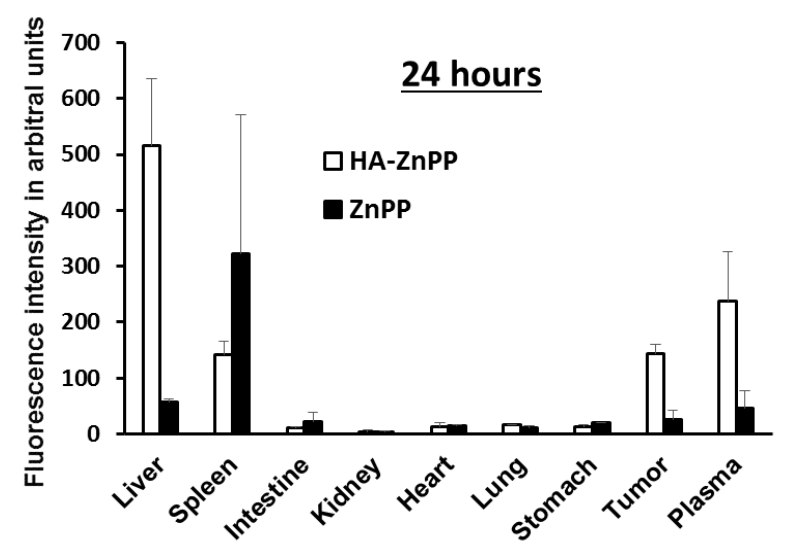

(B)

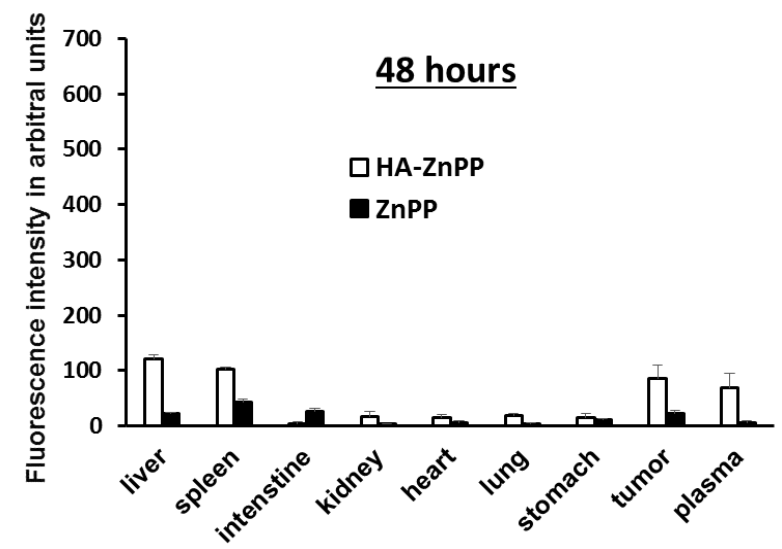

Figure 4: Body distribution of HA-ZnPP in S-180 tumor-bearing mice. S-180 tumor-bearing mice were received ZnPP or HA-ZnPP at $15 \mathrm{mg} Z \mathrm{ZnPP}$-equivalent /kg via the tail vein. At 24 and $48 \mathrm{~h}$ after the ZnPP or HA-ZnPP administration, mice were sacrificed and selected organs were collected after transcardial perfusion with saline. The amounts of the ZnPP after extraction were measured by fluorescence spectrometry $(n=6)$. Experimental details were described in the Materials and Methods. Data were presented as mean \pm SD.

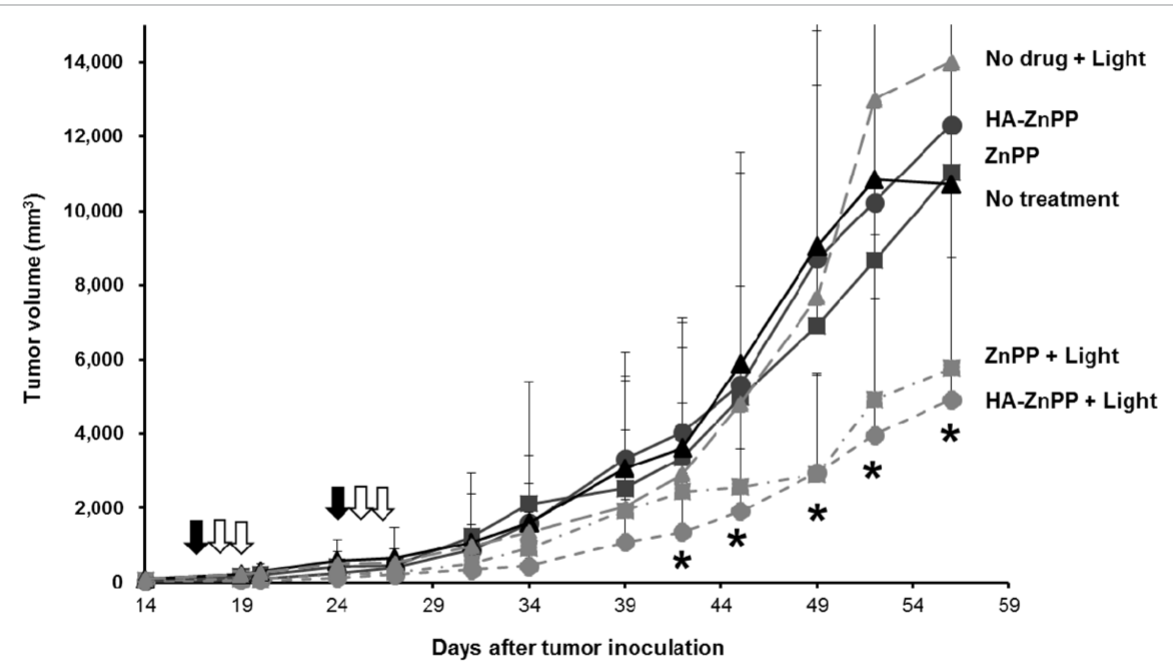

Figure 5: Antitumor effect of HA-ZnPP in S-180 tumor-bearing mice. S-180 tumor-bearing mice were treated with $15 \mathrm{mg} / \mathrm{kg}$ of ZnPP or HA-ZnPP (black arrows) followed by with or without light irradiation (white arrows). Tumor volumes were measured as described in Materials and Methods ( $\mathrm{n}=5)$. Data were presented as mean $+\mathrm{SD} .{ }^{*} P<0.05$ versus HA-ZnPP singly-treated.

longer than that of free ZnPP (Figure 4). Thus, HA-ZnPP successfully accumulated in the tumor tissue by EPR effect and less in the normal tissue. This result indicates that selective targeting of $\mathrm{ZnPP}$ into the tumor tissue can be achieved by hyaluronic acid conjugation to $\mathrm{ZnPP}$.

\section{In vivo antitumor activity of HA-ZnPP}

S-180 tumor-bearing mice at a tumor diameter of 5-8 mm were administered with $\mathrm{ZnPP}$ or $\mathrm{HA}-\mathrm{ZnPP}$ via the tail vein with or without following light irradiation (Figure 5). When ZnPP was singly administered to the model mice without following light irradiation, antitumor activity was not observed at all. A similar trend was also observed for a single administration of HA-ZnPP. Meanwhile a combination of HA-ZnPP and light irradiation suppressed the tumor growth. Severe body weight loss, apparent burn, dermatitis and scar were not observed after the combination of HA-ZnPP and light irradiation. Such antitumor effect by the combination of HA-ZnPP and light irradiation was thought to be due to the singlet oxygen generation, as was shown in Figure 2. Shown in Figure 2 also demonstrated that lecithin added plays a critical role in the generation of ${ }^{1} \mathrm{O}_{2}$ from the HA-ZnPP. Thus, the cell membrane contact and subsequent vesicleassociated cellular uptake of HA-ZnPP were thought to be relevant to the HA-ZnPP cytotoxicity. However, the antitumor activity of HA$\mathrm{ZnPP}$ with following light irradiation was not yet significantly superior to that of free-ZnPP. This may be explained by the HA receptormediated endocytotic activity of S-180 cells inoculated in mice, since the activity of the HA receptor-mediated endocytosis is generally known to be largely dependent on tumor cell types [17].

\section{Conclusions}

In this study, we synthesized a conjugate of zinc protoporphyrin and hyaluronic acid (HA-ZnPP), and determined the in vitro and in vivo behavior of HA-ZnPP. Aqueous solubility of $\mathrm{ZnPP}$ was highly improved, however ${ }^{1} \mathrm{O}_{2}$ generation was quenched, unless in the presence of detergent such as lecithin. HA-ZnPP was selectively accumulated in 
Citation: Eguchi K, Nakamura H, Zhou JR, Jun F, Yokomizo K, et al. (2017) Hyaluronic Acid-zinc Protoporphyrin IX Conjugates for Photodynamic Antitumor Therapy. J Nanomed Nanotechnol 8: 440. doi: 10.4172/2157-7439.1000440

Page 6 of 6

the tumor tissue, and tumor growth was suppressed by combination of $\mathrm{HA}-\mathrm{ZnPP}$ and light irradiation without severe adverse effects. Overall, $\mathrm{HA}-\mathrm{ZnPP}$ is a promising candidate for photosensitizing agent for antitumor therapy.

\section{References}

1. Hamori CJ, Vreman, HJ, Rodgers, PA, Stevenson DK (1989) Zinc protoporphyrin inhibits $\mathrm{CO}$ production in rats. Journal of Pediatric Gastroenterology and Nutrition 8: 110-115

2. Fang J, Sawa T, Akaike T, Akuta T, Sahoo SK, et al. (2003) In vivo antitumor activity of pegylated zinc protoporphyrin: targeted inhibition of heme oxygenase in solid tumor. Cancer Research 63: 3567-3574.

3. Siow RCM, Ishii T, Sato H, Taketani S, Leake DS, et al. (1995) Induction of the antioxidant stress proteins heme oxygenase- 1 and MSP23 by stress agents and oxidised LDL in cultured vascular smooth muscle cells. FEBS Letters 368 : 239-242.

4. Clark JE, Foresti R, Green CJ, Motterlini R (2000) Dynamics of haem oxygenase-1 expression and bilirubin production in cellular protection against oxidative stress. Biochemical Journal 348: 615-619.

5. Soares MP, Usheva A, Brouard S, Berberat PO, Gunther L, et al. (2004) Modulation of endothelial cell apoptosis by heme oxygenase-1-derived carbon monoxide. Antioxidants and Redox Signaling 4: 321-329.

6. Tanaka S, Akaike T, Fang J, Beppu T, Ogawa M, et al. (2003) Antiapoptotic effect of haem oxygenase-1 induced by nitric oxide in experimental solid tumour. British Journal of Cancer 88: 902-909.

7. Sahoo SK, Sawa T, Fang J, Tanaka S, Miyamoto Y, et al. (2002) Pegylated zinc protoporphyrin: a water-soluble heme oxygenase inhibitor with tumortargeting capacity. Bioconjugate Chemistry 13: 1031-1038.

8. Fang J, Greish K, Qin H, Liao L, Nakamura H, et al. (2012) HSP32 (HO-1) inhibitor, copoly(styrene-maleic acid)-zinc protoporphyrin IX, a water-soluble micelle as anticancer agent: In vitro and in vivo anticancer effect. European Journal of Pharmaceutics and Biopharmaceutics 81: 540-547.
9. Fang J, Sawa T, Akaike T, Maeda $\mathrm{H}$ (2002) Tumor-targeted delivery of polyethylene glycol-conjugated $\mathrm{D}$-amino acid oxidase for antitumor therapy via enzymatic generation of hydrogen peroxide. Cancer Research 62: 3138-3143.

10. Chilakamarthi U, Giribabu L (2017) Photodynamic Therapy: Past, Present and Future. The Chemical Record.

11. Fernandez JM (1997) Singlet oxygen generation by photodynamic agents Journal of Photochemistry and Photobiology B: Biology 37: 131-140.

12. Iyer AK, Greish K, Fang J, Murakami R, Maeda H (2007) High-loading nanosized micelles of copoly(styrene-maleic acid)-zinc protoporphyrin for targeted delivery of a potent heme oxygenase inhibitor. Biomaterials 28 : 1871-1881.

13. Nakamura H, Liao L, Hitaka Y, Tsukigawa K, Subr V, et al. (2013) Micelles of zinc protoporphyrin conjugated to $\mathrm{N}$-(2-hydroxypropyl)methacrylamide (HPMA) copolymer for imaging and light-induced antitumor effects in vivo. Journal of Controlled Release 165: 191-198.

14. Tanielian C, Wolff C (1995) Porphyrin sensitized generation of singlet molecula oxygen: comparison of steady-state and time resolved methods. The Journal of Physical Chemistry 99: 9825-9830.

15. Hatakeyama $\mathrm{H}$, Akita $\mathrm{H}$, Harashima $\mathrm{H}$ (2013) The polyethyleneglycol dilemma: advantage and disadvantage of PEGylation of liposomes for systemic genes and nucleic acids delivery to tumors. Biological and Pharmaceutical Bulletin 36: 892-899.

16. Tsukigawa K, Nakamura H, Fang J, Otagiri M, Maeda H (2015) Effect of different chemical bonds in pegylation of zinc protoporphyrin that affects drug release, intracellular uptake, and therapeutic effect in the tumor. European Journal of Pharmaceutics and Biopharmaceutics 89: 259-270.

17. Matsumura $Y$, Maeda $H$ (1986) A new concept for macromolecular therapeutics in cancer chemotherapy: mechanism of tumoritropic accumulation of proteins and the antitumor agent smancs. Cancer Research 46: 6387-6392.

18. Racine R, Mummert ME (2012) Hyaluronan endocytosis: mechanisms of uptake and biological functions. InTech. 